\title{
LA ESVASTICA EN ARMAS ANTIGUAS \\ Relaciones Iconográficas del Símbolo y Estimaciones sobre su Posible Significado
}

\author{
POR \\ JUAN-EDUARDO CIRLOT
}

\section{Preámbulo}

EL primer hecho que debe mencionarse a propósito de la esvástica, cruz gamada o gammadion es que, hasta el presente, no se ha encontrado nunca en monumentos prehistóricos en el Próximo Oriente ni en objetos anteriores a la Edad del Hierro en Occidente. En pinturas paleolíticas se han hallado abundantes signos gráficos, sobre cuya interpretación distan de estar de acuerdo los prehistoriadores: rayas, series de trazos, de puntas, flechas, signos tectiformes, series de arcos de circunferencia, arpones, rombos, rejillas, cruces y aspas. Pero nunca esvásticas. El carácter de todos los signos que hemos citado, a excepción de los tectiformes y de los arcos concéntricos de circunferencia, permite atribuir su hallazgo al azar o al gesto instintivo. La esvástica es tan marcadamente intencional que sólo una idea concreta puede darle origen. Cabría suponer que nació de superposiciones de grecas, si no fuera más antigua que ellas (las más antiguas esvásticas conocidas datan de finales del cuarto milenio antes de nuestra Era). También sucede lo mismo con las ruedas de trazos sigmoideos, de los que pudiera ser una simplificación, pero esas ruedas son también posteriores. En cuanto a su parentesco con los símbolos solares (disco, disco con rayos, disco con dos cruces, la normal y el aspa, trazos convergentes solos señalando la irradiación de luz y calor) es poco menos que nulo. El origen de la esvástica es desconocido. En cuanto a su distribución, a partir de un centro que cabe situar entre el Cáucaso y Mesopotamia - tanto hacia Oriente, hasta el Japón (trayectoria que no vamos a estudiar), como hacia Occidente, lo mismo puede proceder del fenómeno de «invención simultánea» que de la «migración» del símbolo. Ambas teorías, aplicables a todo descubrimiento humano (el fuego, la cerámica, etc.), tienen sus defensores y no ha probado nadie hasta el presente quiénes tienen razón. 


\section{ESVÁSTICAS EN ARMAS}

Dando a este concepto el valor más amplio, hemos de reconocer que el material encontrado no es abundante. Se reduce a un «estandarte», o mejor, enseña hitita, a una lanza hallada en Brandeburgo, a una espada céltica, a una placa protectora de cinturón, hallstática, a un casco romano. La pieza más antigua es, sin duda, la enseña hitita, que fue encontrada en Alaca Hüyük, y que data de hacia el 2000 antes de Jesucristo, aunque es

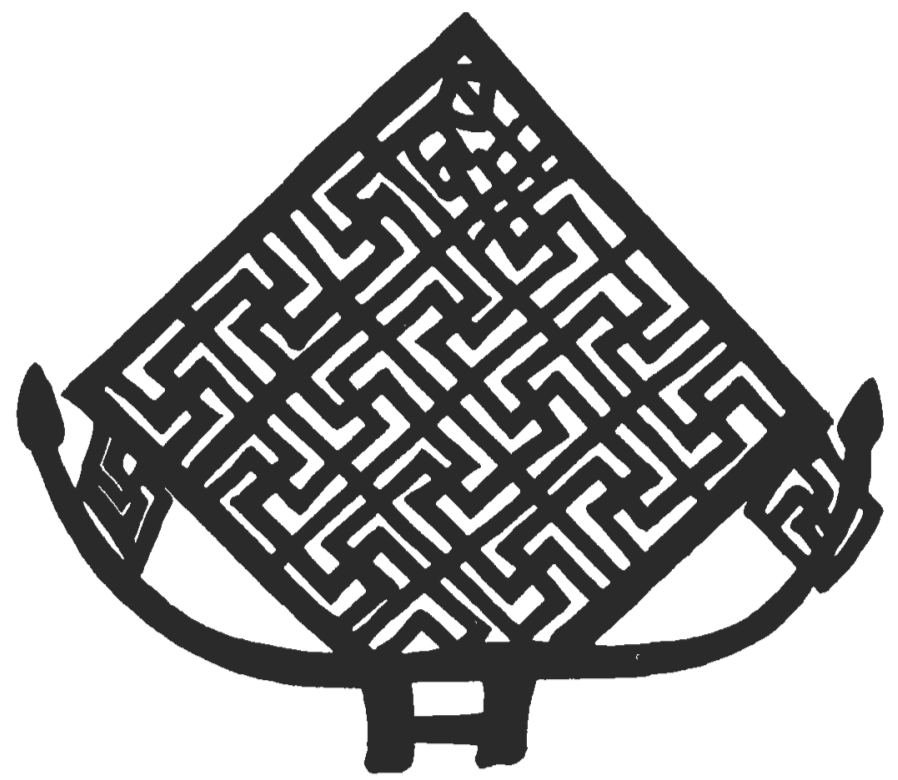

Fıg. 1.-Estandarte bitita. Alaca Hüyük. Ca. 2000 antes de Jesucristo (Museo Arq. Ankara).

probable que la fecha varíe en un ámbito de varios siglos, aproximándose hacia la época en que los hititas, como avanzada aria en Asia Menor, descendiendo a Siria, se enfrentaron con los egipcios de la XX dinastía. Esta enseña, en su conjunto, parece una reja, y por su forma -en términos simbológicos-, no deja de poseer cierto contexto solar, ya que el cuadrado dispuesto con las esquinas arriba y abajo posee un carácter dinámico que la doctrina tradicional asocia a los cultos solares. Es innegable 
que el movimiento del metal dibuja una serie de esvásticas perfectamente claras, sin lugar a duda; pero también es cierto que el signo, como tal, no aparece «entronizado», es decir, sublimado por el refuerzo de valor que da la unidad. La insignia se asemeja, grosso modo, a las de los nomos egipcios del período, y es sabido por todos los que se han interesado por la egiptología que las enseñas de nomos (provincias, distritos, grupos), con carácter civil (y militar a la vez, seguramente), ya existían en el Egipto de la primera dinastía, hacia el 3100 antes de Jesucristo.

Fig. 2.--Placa de cinturón. Hierro. Epoca de Hallstatt (1000500 a. de J. C.), de Hundersingen (Württ.) (Landesmuseum, Stuttgart).

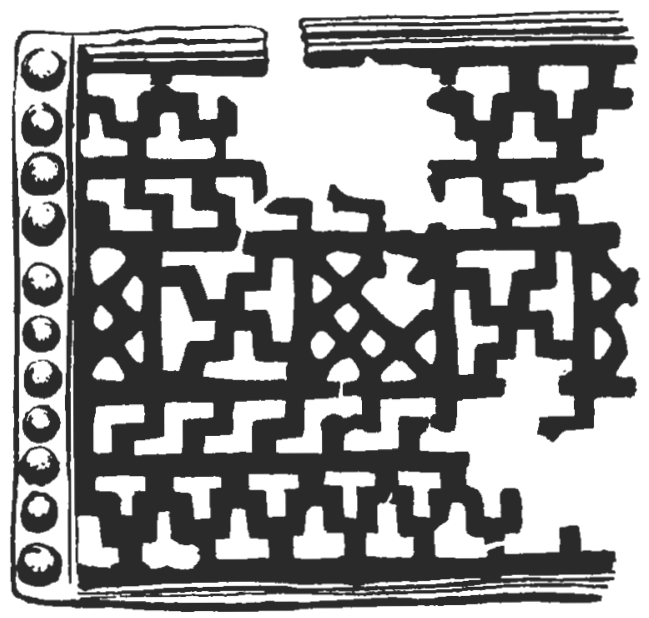

La placa de cinturón pudiera ser la segunda, cronológicamente, de las piezas citadas. Siempre hemos abrigado la intuición de que, en ciertos pueblos (por ejemplo, más tardíamente, entre los visigodos), ciertos objetos de adorno podían ser distintivos raciales, de ahí la constancia de su forma y su abundancia. Entre esos objetos prevalecen dos, sin duda de antigua raigambre: las placas de cinturón y las fíbulas. Esta placa, calada, de la que damos sólo un fragmento de la parte conservada, es bastante similar a la enseña hitita. Respecto a los hallazgos de la metalurgia, primero el bronce y luego el hierro, no se duda en que, muy posiblemente, se difundieron de las zonas donde había estaño y cobre (Asia Menor, etc.) hacia Oriente y Occidente. Esa vía pudo seguir el esquema hitita hasta Württemberg, lugar donde se halló la placa. Ciertamente, es distinta de la mayoría de hallstáticas de Germania, que no suelen ser caladas ni 
acostumbran a presentar esvásticas, al menos las que conocemos. En esta pieza, el símbolo ya aparece destacado entre otros esquemas lineales más difusos que forman como enmarcamientos. Rasgos que unen la $U_{\text {y }}$ la $T$ se hallan en la zona más baja; en el arte viking, en ocasiones, aparecen ligados a la esvástica.

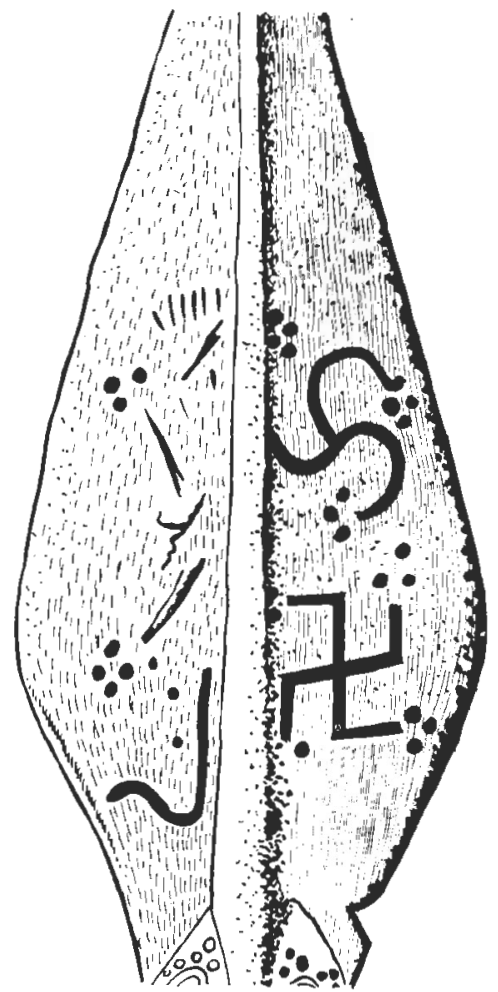

Fig. 3.-Hierro de lanza, ballada en Brandesburg. 1000-500 antes de Jesucristo.

El hierro de lanza, también del mismo período, entre el 1000 y el 500 antes de Jesucristo, aproximadamente, es interesante porque asocia a la esvástica otros signos, el más acusado y característico de ellos es el triskeles de trazos curvos, que sí suele tener simbolismo solar, mientras que 
la esvástica, como veremos finalmente, al parecer no lo tenía. Avanzaremos que, en nuestra opinión, los artesanos que trabajaron estas piezas o grabaron estos signos a posteriori no tenían forzosamente que conocer su significado ortodoxo; más bien los empleaban como amuletos protectores, o por obedecer a una lejana tradición que veneraban sin discernir su razón de ser. Las series de puntos grabados en la hoja de lanza, por su modo de agruparse, no parecen tener sentido planetario, sino ornamental.
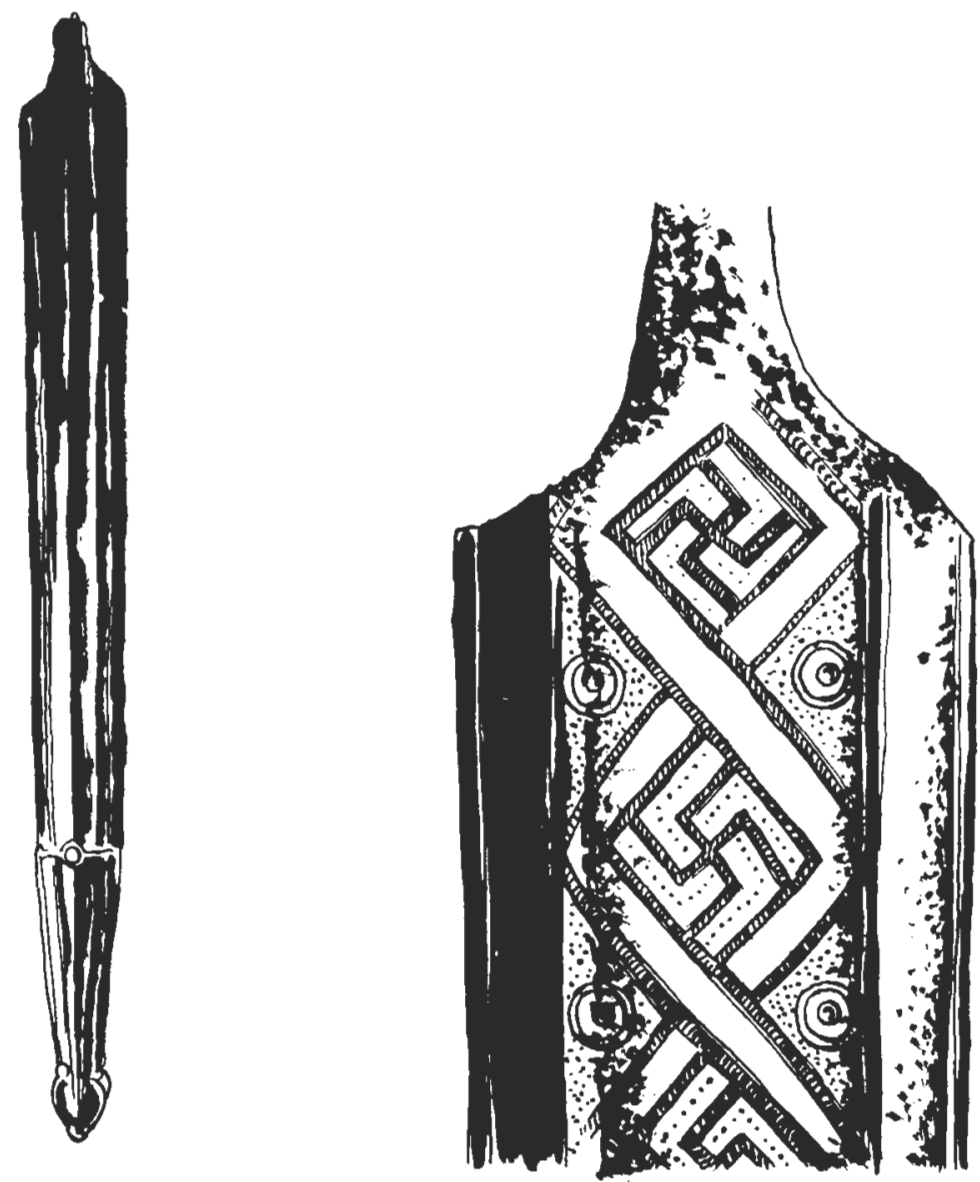

Fig. 4.-Espada de Vers-la-Gravelle. Céltica. Ca. 500 antes de Jesucristo (Berlín. Museum für Vor- u. Frühgeschichte). 
Obsérvese con qué fuerza destacan los ángulos rectos de la esvástica en contraposición con las más suaves formas del triskeles. Sin duda se trata de un arma de jefe, como se advierte por la ornamentación que prosigue en el inicio del tubo, perceptible.

Más importante, y tardía, es la hermosa hoja de espada de Vers-laGravelle, obra céltica que seguramente data de la época de La Tène, es decir, de los años 450 antes de Jesucristo al principio de nuestra Era. Con todo, la tradición hallstática se mantiene por el predominio, en la

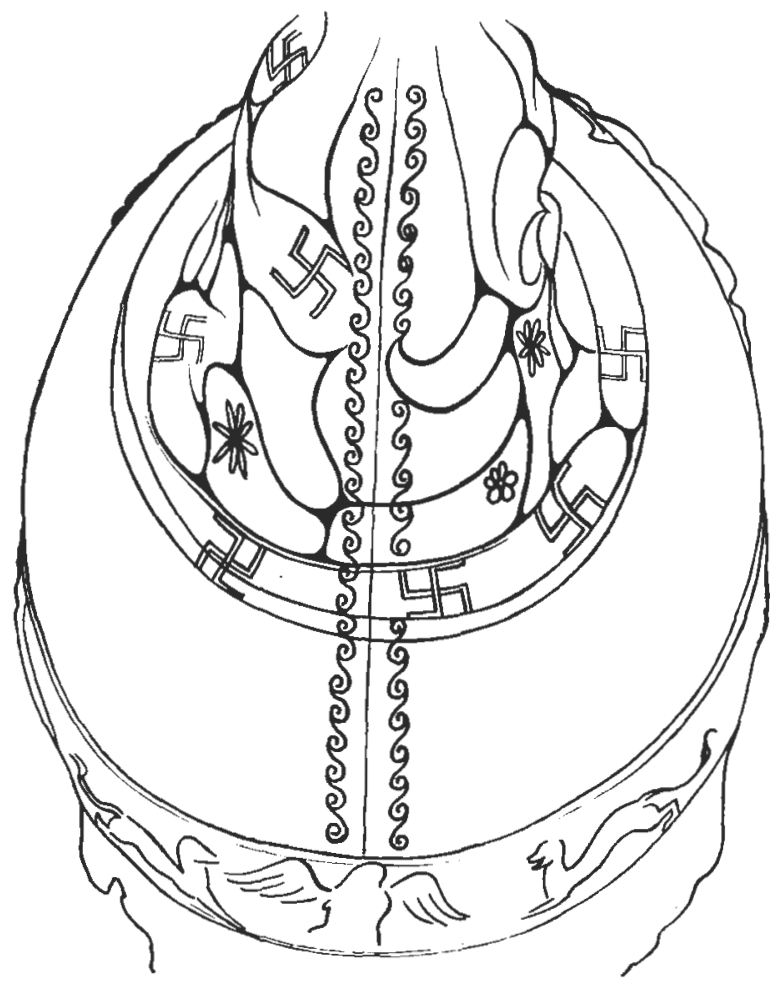

FIG. 5.-Yelmo romano con siele esváslicas. Hacia siglos I-III después de Jesucristo.

ornamentación, de todo lo rectilíneo sobre lo curvilíneo - - tan decisivo en lo celta puro- Las esvásticas aparecen alojadas en compartimientos bien delimitados, en rombos cuyas puntas relativas al eje principal están en la vertical. Los discos que sirven de complemento tienen un punto central y un anillo. Pudieran ser meros adornos, o ser también elementos 
de carácter simbólico. El bronce aparece trabajado con una finura fuera de lo corriente. Signográficamente, es importante el hecho de que en esta pieza, como en la placa de cinturón de Württemberg, y en el estandarte hitita, los extremos de la cruz gamada se unen al marco y dan lugar así a un movimiento generalizado, exaltando el sentido - ya de sí dinámicoque caracteriza siempre a la esvástica. En esta hoja de espada ya no hay problema de origen, en lo que al símbolo se refiere; en todo el primer milenio antes de nuestra Era la esvástica se había difundido por Eǔopa, desde Micenas (aquí antes) al Oeste, llegando, seguramente con los celtas, a España, donde se ha encontrado en la cerámica numantina del siglo II antes de Jesucristo.

Por último, hemos de considerar un casco romano que, por presentar siete esvásticas, se diría relacionado con un culto planetario o acaso mitraico. Por la estructura del casco, debe tratarse de una obra de época imperial (ya no tiene ninguna reminiscencia helénica en la forma), y es muy difícil de fechar con exactitud, pudiendo ser del siglo I al in después de Jesucristo, verosímilmente. Pese a lo antes afirmado, el hecho de que haya siete esvásticas podría no tener ningún contexto religioso ni simbólico y ser una mera repetición - a una cifra que siempre tuvo un valor casi mágico- del signo que se supuso de «buen augurio». Los romanos lo tomaron posiblemente de los etruscos y acaso de las culturas anteriores a éstos. En urnas cinerarias del 800 al 600 antes de Jesucristo aparecen esvásticas trazadas, como en el ejemplo, rematado por un yelmo, que reproducimos. El septenario de esvásticas del casco romano, cuyo origen no conocemos (es decir, su lugar de hallazgo, pero que suponemos debe ser Francia por derivar este dibujo de un documento de la Biblioteca Nacional de París), termina con lo que podemos decir sobre las esvásticas en armas romanas. En la famosa turbera de Vimose, en Fionia (Dinamarca), se han hallado, entre otras armas, algunas puntas de flecha de hierro y de hueso. Entre ellas se halla un especimen de hueso con dibujo de esvástica de la época 200-400 después de Jesucristo. La esvástica penetró tamhién en la Inglaterra anglosajona, probablemente por medio de los invasores sajones, aunque también pudieron llevarla antes los romanos, que la usaron ampliamente en mosaicos, armas y otros elementos decorativos. Según Davidson, en The Sword in Anglo-Saxon England (1962), la esvástica fue usada con carácter talismánico, o apotropaico, en diversos objetos de uso personal, e indudablemente - lo que nos interesa esencialmente dado el fin de este texto- en armas. Tanto en las vainas como en pomos de espada del período comprendido entre los siglos VI y VIII aparecen pequeñas esvásticas situadas en el centro o a un lado de la pieza. Es frecuente que se trate de un solo signo; pero hay piezas en las que éste aparece repetido varias veces, como si su multiplicación acrecentara 
su potencia mágica, como en una placa de cinturón de Bifrons, en Inglaterra. En los siglos XI a XIII algunas hojas de espada presentan, aparte de cruces griegas o latinas, cruces gamadas, que han de interpretarse como mera reminiscencia apotropaica de tiempos pasados. En hojas de espadas de cruzados se han hallado tales signos, solos o al lado de inscripciones diversas. Más tarde, la esvástica se hace más rara, sobre todo en las comarcas meridionales de Europa. Como marca de espadero, aparentemente, no se encuentra en los repertorios publicados. Si los antiguos creyeron que

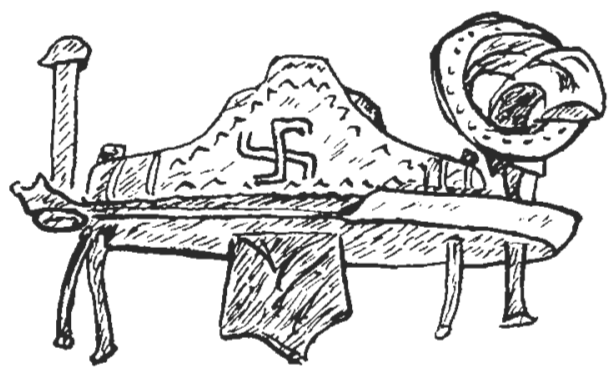

Fig. 6.--Pomo de espada anglosajona con esvástica. Bifrons (Inglaterra) (Maidstone Museum).
Fig. 7.-Punta de flecha de bueso con esvástica. Siglo IIIT-IV despuês de Jesucristo. Vimose (Dinamarca) (Museo Nacional, Copenhague).

la esvástica tenía un carácter protector es lógico que la grabaran en las armas, así como en la Edad Media se grababa en las hojas de las espadas la cruz de Cristo, y en los siglos XVI-XvII, divisas relativas a Dios, la Virgen o los santos.

\section{ORIGEN Y DIFUSIÓN DE LA ESVÁSTICA, ALGUNOS EJEMPLOS}

Es interesante ejemplarizar, «envolver», los tipos señalados hasta aquí con otros que, sin pertenecer a armas, nos iluminan sobre las áreas de difusión y las fechas de la esvástica. Lo repetimos: prescindimos del 
Extremo Oriente (donde se hallan, desde el Tibet al Japón) y también de América (donde aparecen en dibujos y tejidos de los indios).

La esvástica más antigua conocida se halla en una pieza de cerámica de Susa, de hacia 3500-3000 antes de Jesucristo. Aparece repetida, en simetría bilateral, centrando un cuádruple triángulo que forma una cruz. «Peines» y triples trazos quebrados enmarcan este grupo. Dada la diversa y rica iconografía de la cerámica susiana, es difícil hacer conjeturas al

Fig. 8.-Cerámica de Susa (Elam). Final del cuario milenio antes de Jesucristo.

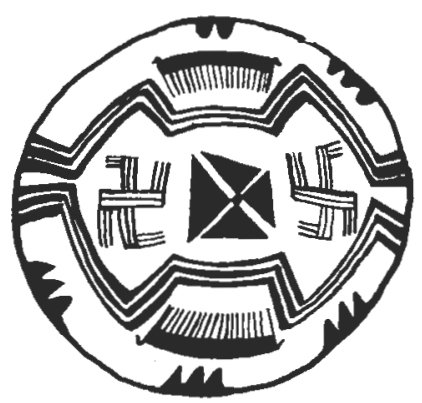

respecto. Esa cultura no se conoce bien en su ideología y sería arriesgado pronunciarse sobre el sentido del signo, aunque lo más probable es que sea meramente talismánico si, con Marius Schneider, no admitimos que jamás, en las culturas antiguas, existiera «ornamentación pura», es decir, arte por el arte. Algo posterior es otra esvástica, también en el fondo de un cuenco cerámico (hacia 3000-2500 antes de Jesucristo), hallado en Shahi-tump, que pudo corresponder a la civilización de Harappa, cuyos

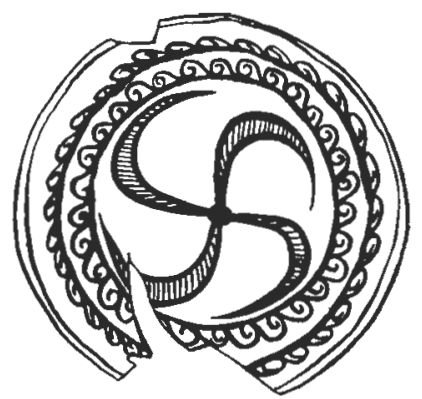

Fig. 9.-Plato procedente del cementerio de Shabitump. (Central Asia Museum, Delhi.) ¿Civilización de Harappa? 3000-2500 antes de Jesucristo. 
contactos con el mundo mesopotámico son conocidos. Es interesante el hecho de que aquí encontramos una sola esvástica, bien centrada y valorada, es decir, «reconocida» en su significación presunta. De otro lado, sus trazos (como luego sucederá en Micenas y Creta) son curvilíneos. Pero de la misma fecha, o algo posterior (hacia 2000 antes de Jesucristo), es un sello procedente de Harappa, con una esvástica cuadrada, tratada

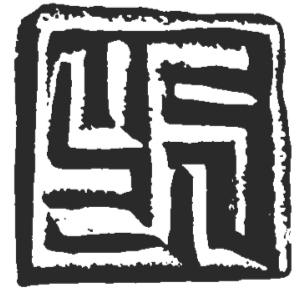

Frg. 10,-Sello. India. Cultura de Harappa. Ca. 2000 a. de J. C.

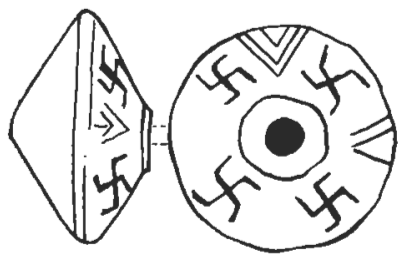

FIG. 11.-Pesa de bilar. Troya. Hacia 2200-2000 a. de J. C.

en intenso y formal relieve que subraya la forma del objeto. ¿Quién usó este sello? ¿Qué valor le dio? Son preguntas sin posible contestación, nos parece. En Troya se han encontrado esvásticas en abundancia, grabadas o trazadas ligeramente en diversos objetos, desde las pesas de telar a los ídolos de la fecundidad. Esto parece aclarar que se les atribuía un valor acaso «complementario» de lo femenino más que una mera aptitud

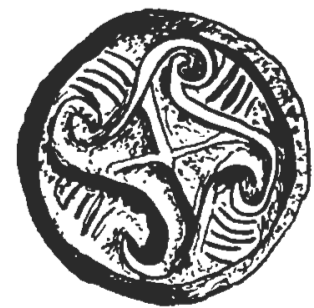

Fig. 12.- Jello cretense. Hacia 2000 antes de Jesucristo.

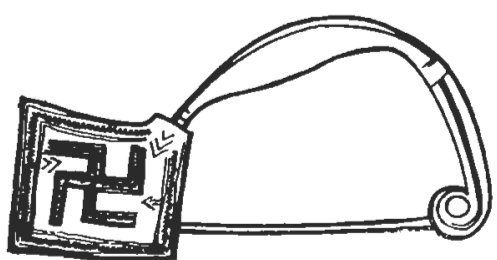

FIG. 13. - ribula de oro, griega. Hacia 700 antes de Jesucristo (Londres. British Museum).

para aportar «buena suerte». Si comparamos el sello cretense que reproducimos (de hacia 2000 antes de Jesucristo o algo más tarde) con la fíbula griega de oro, de hacia 700 antes de Jesucristo, veremos de nuevo el contraste entre la forma curvilínea y la rectangular. ¿Es un pathos racial el que imponía una u otra preferencia? ¿O más bien un principio geocultural? Nos inclinaríamos por lo segundo, aunque la violencia de 
las cuatro gammas es innegable, mientras que la esvástica curva o sus derivaciones se aproximan a los símbolos del mar y del abismo (espirales, laberintos). En Grecia encontramos, sobre todo en la cerámica, variadas

FIG. 14.-Crátera del Atica. Siglo viI-vi antes de Jesucristo (Londres. British Mu-

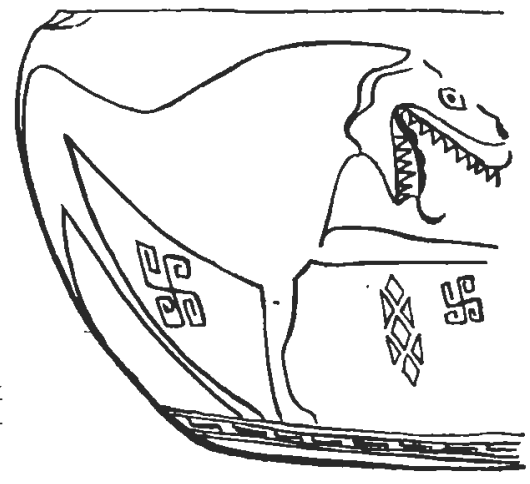

formas de esvásticas, pero se trata de «variaciones ornamentales» más que simbólicas, a nuestro modo de ver; la manera indiferente de su distribución, en medio de escenas figurativas, parece probar que se trata de

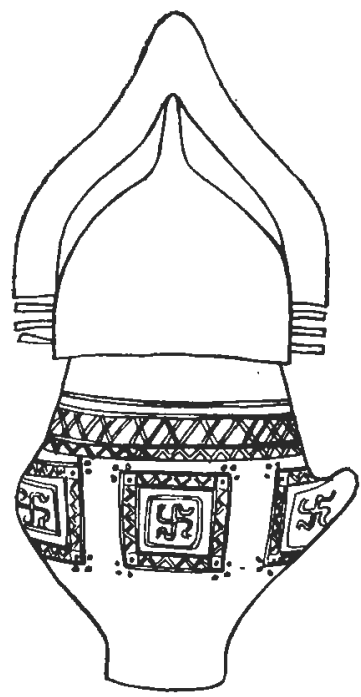

FIG. 15.-Urna con yelmo, de Tarquinia. Etruria. Siglo viri antes de Jesucristo (Corneto). 
adornos o de signos con valor talismánico, pero no de símbolos a los que se atribuyera gran poder. Ya citamos la urna itálica de hacia 800-600 antes de Jesucristo. De parecida época debe ser la piedra grabada de Robernier, Var (Francia), hallstática, que se ha considerado (hemos de admitir, hasta cierto punto, que razonablemente) como símbolo solar por

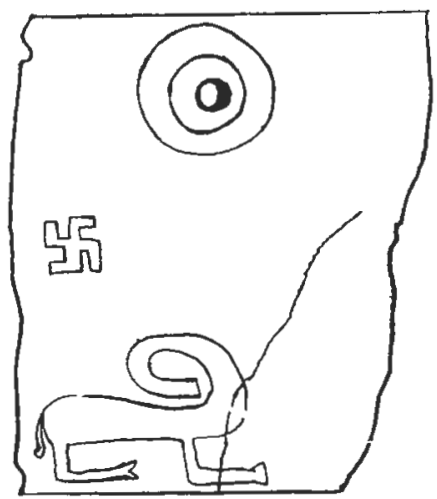

Fig. 16.-Piedra grabada, de Robernier, Var (París. Museo de Saint-Germain). Epoca de Hallstatt.

aparecer junto al caballo (a veces, no siempre, símbolo solar) y al círculo con elementos internos (ídem). Pero también pudiera tratarse de otra simbología más rica y compleja: Sol (disco), vida, actividad (esvástica), muerte (caballo, que también aparece asociado a cultos funerarios).

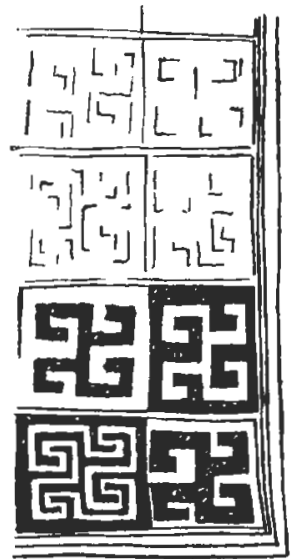

Fig. 17.-Tejido del Cálucaso (anterior a nuestra Era). 
Volviendo al Próximo Oriente, hallamos la esvástica en tejidos y bordados caucásicos de pocos siglos antes de nuestra Era, derivación lógica de los signos idénticos de períodos muy anteriores, de procedencia hitita o asiria. Este último pueblo valoró mucho la esvástica.

F1G. 18.-Cerámica de Numancia. Sigio $n$ antes de Jesucristo (Soria. Museo Numantino).

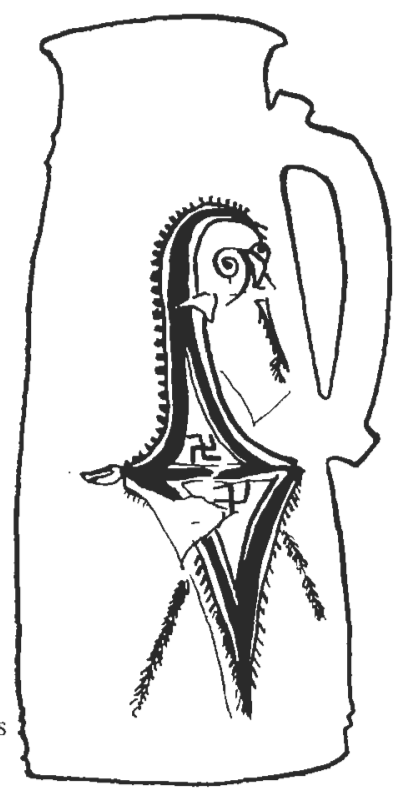

Es curioso que la hallemos, ya en nuestra Era, tanto en la epigrafía pagana como en la cristiana. En catacumbas, junto con inscripciones, se han encontrado —al lado de la cruz griega- esvásticas. Y algunos monumentos irlandeses de los siglos vi a viII también la ostentan, asociada a

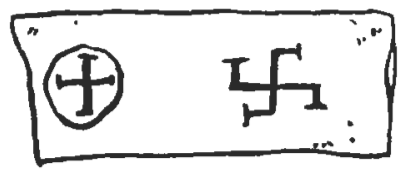

FIG. 19.- Esvástica en una caiacumba cristiana. Siglo III después de Jesucristo.

la cruz latina, griega o no. Entre las esvásticas irlandesas más netas se hallan las de la cruz de Cloon Lough (Kerry, siglo vir después de Jesucristo). En cambio, el pueblo de los ávaros nos facilita, en fíbulas y otros objetos de adorno, esvásticas «figurativas» como la constituida por cuatro 
cabezas y cuellos de caballo (o de un animal fabuloso que se le asemeja), que se reproduce, obra coetánea a las cruces gamadas de Irlanda antes mencionadas. Entre los vikings y pueblos bálticos se halló muy difundida,

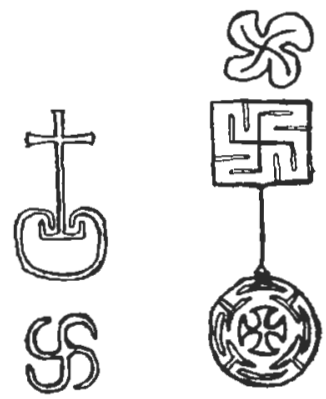

FIG. 20.-Dibujos grabados en la cruz de Cloon Lough (Kerry, Irlanda). Siglo vir.

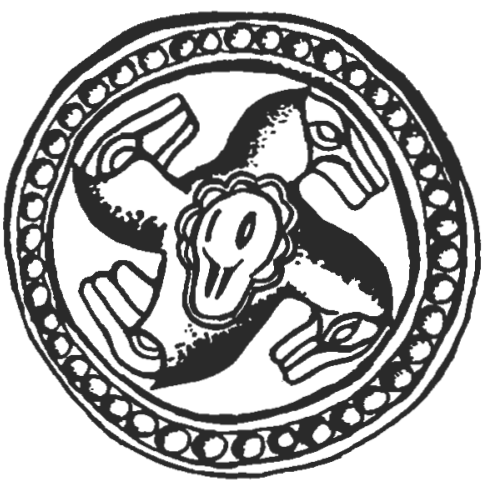

FIG. 21.-Falera de bronce. Cultura de los ávaros. Siglo vir después de Jesucristo (Budapest. Museo Nacional Húngaro).

y son conocidas las relaciones culturales de esos pueblos con la civilización celtogermánica. Una bracteada de Gerete, del siglo v-vi, la muestra tras la cabeza de un personaje, como protegiéndole. En tejidos, la vemos asociada a la tau (T). Es curiosa la piedra de Visby, sin duda de época tardía

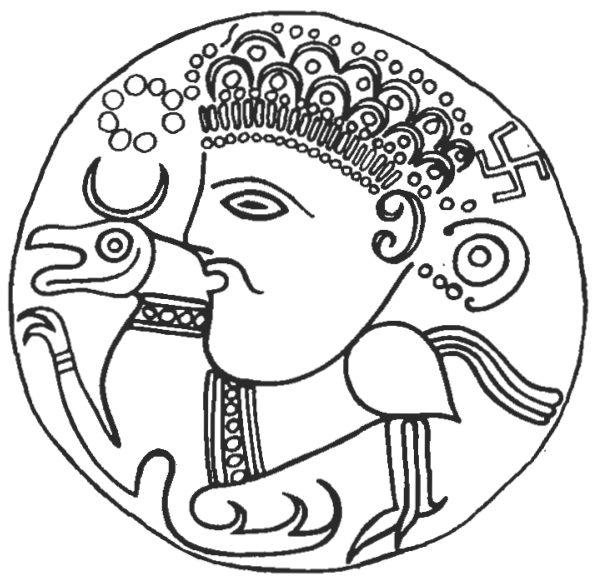

Fig. 22.-Bracteada de oro de Gerete (Golland). Siglo v-vi (Estocolmo. Museo de Antigüedades Nacionales). 
viking, con una esvástica curvilínea en su parte superior. Es particular la forma compleja de las esvásticas bálticas de la fíbula, del siglo xI, del

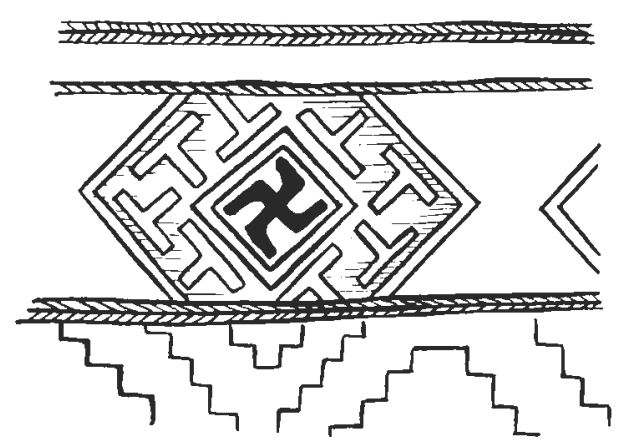

FIG. 23.-Tejido viking. Siglo vII-vIII.

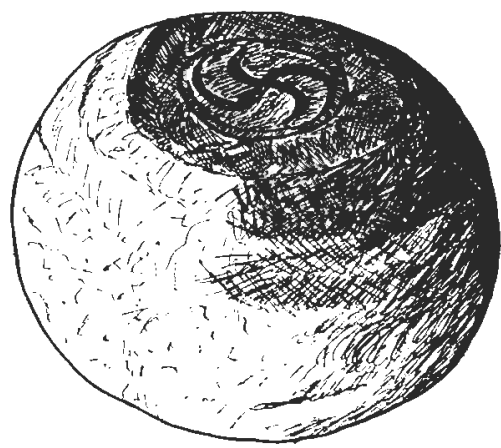

FIG. 24.-Piedra esférica con esvástica, de Myrvalder en Tingsiäde (Gol(and).

Istorinis Muziejus de Kaunas. Los brazos principales casi son rectos y las terminaciones parecen ganchos.

F1G. 25.-Fíbula. Países bálticos. Siglo XI (Kaunas.

Istorinis Muziejus).

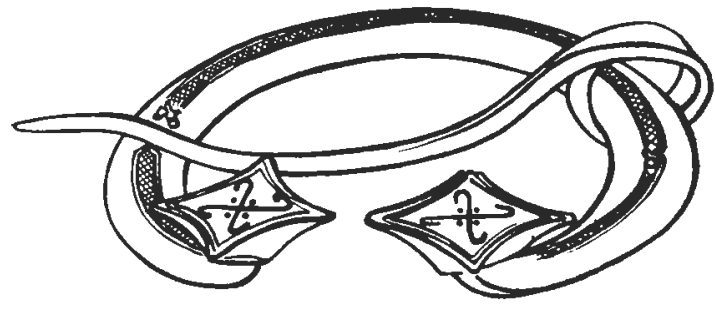

Significado DeL SÍmbolo

H. M. Raphaelian le atribuye valor de símbolo de fertilidad, es decir, de fecundidad. Señala su presencia en Mesopotamia, India, Asia Menor, Grecia, Chipre, Rodas, Italia, España, Galias, Germania, Danubio, Cáucaso, etc. Jean Marques Rivière, que la juzga un mero talismán. Para Marius Schneider, la esvástica (semejante a la figura del arquero arrodi- 
llado) es el «símbolo central de las relaciones entre el cielo y la tierra». Goblet d'Alviella era partidario de la teoría solar (en un tiempo todos los símbolos eran solares, como en otro todos lo fueron sexuales). Pero René Guénon, en sus profundas obras, considera que la esvástica la vio el hombre en el cielo, asistiendo a la rotación de la Osa Mayor en torno a la estrella polar y situando los cuatro momentos esenciales de esa rota-

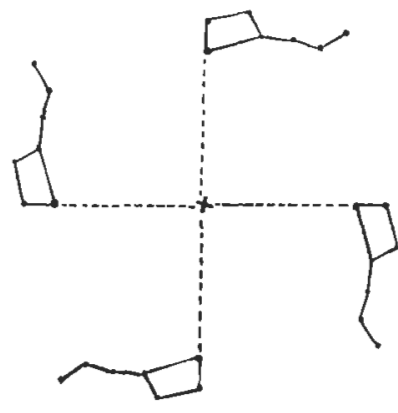

FIG. 26.-Rolación aparente de la Osa Mayor en torno a la estrella polar.

ción. (Damos el esquema dibujado.) De ahí que la considere como símbolo del Polo (Norte) y que, en tal concepto, fuera aceptada por quienes creían que su raza procedía de las comarcas árticas, de un reino mítico (Thule u otro), verdadero «centro del mundo» asimilado al centro de la esvástica. La rotación «potencial» que marca el signo de la cruz gamada, por sí mismo, también ha sido interpretado como fuerza, acción, como violencia del martillo de Tor (cada uno de los brazos), captado en cuatro posiciones, asimilables a las de la Osa Mayor en el cielo. Es difícil decidir sobre el sentido del símbolo. Pero es evidente que los símbolos actúan. Como dijo Gaston Bachelard, «para partir sobre las olas agitadas hacen falta intereses muy grandes, y los intereses muy grandes son los quiméricos».

\section{B I B LIOGR AFIA}

BranN, Friedrich: Vorgescbichllicbe Welt. Stuttgart, 1962.

Cirlot, J.-E.: Diccionario de símbolos. Barcelona, 1969.

Champo y Stekek: Symboles. Yonne, 1966.

Davidson, H. R. Ellis: The Sword in Anglo-Saxon England. Oxford, 1962.

Erdély, Istvan: The Art of the Avars. Budapest, 1966.

Gimbutasm Marija: The Balts. Londres, 1963. 
Gordon Childe: L'Orient Prébistorique. París, 1953

Grappin, P.: Mytbologie germanique. París.

Guénon, René: Il Re del Mondo. Roma, 1952.

Guénon, René: Symboles fondamentaux de la Science sacrée, París, 1962.

Hafner, German: Kreta und Hellas. Baden-Baden, 1968.

Henry, Françoise: L'Art illandais (3 vols.). Yonne, 1963.

Ions, Veronica: Indian Myibology. Londres, 1967.

Kübler, Karl: Allalliscbe Malerei. Tubinga, 1950.

Lekol-Gourinn, A.: Prébistoire de l'Art Occidental. París, 1967.

Marques Rivière: Amulettes, lalismans et pantacles. París, 1950.

Marucchi, Horace: Eléments d’Archéologie Cbrétienne. París, 1903.

Oxenstierna, Eric: The World of the Norsemen. Londres, 1957.

Pijońn, José: El arte prebistórico europeo, vol. VI de Summa Artis. Madrid, 1961. Raphaelian, H. M.: Signs of Life. Nueva York, 1957.

Schneider, Marius: El origen musical de los animales-simbolos en la mitología y escultura anliguas. Barcelona, 1946.

Vacano, Otto von: Die Elrusken. Utrecht, 1961.

Revista Janus, núm. 16, París, s. d.

Pracbisiorische Zeitschrift, vol. XXV. Berlín, 1934.

$\mathrm{Y}$ diversos catálogos de museos, etc. 